\title{
NILAI-NILAI PENDIDIKAN ISLAM DALAM NOVEL SURGA YANG HARUS KU JAGA KARYA SEAN HASYIM (PENDEKATAN PRAGMATIK RESEPTIF)
}

\author{
Syamsul Ma'arif \\ SDN Wanar, Kecamatan Pucuk, Kab. Lamongan \\ HP 081330931190; pos-elsyamsulhand@gmail.com
}

\begin{abstract}
Abstrak: Penelitian ini berlatar belakang pendidikan Islami, yaknipendidikan yangdikembangkan dari nilaifundamental yang terkandung dalam Al-Qur'andan AlHadist. Dalam penelitian ini menggunakan media novel. Sedangkan Novelyang bisa menjadi media pendidikan adalah novel yang memuat nilai-nilai yang mendidik manusia. Yakni cerita yang mampu mendidik akal budi, imajinasi dan etikaseorang anak, serta mengembangkan potensi pengetahuan yang dimiliki. Tujuan penelitian ini adalah (1) mendeskripsikan nilai-nilai Pendidikan Islam yang terkandung dalam novel Surga Yang Harus Ku Jaga Karya Sean Hasyim; (2) untuk mengetahui relevansi nilainilai Pendidikan Islam yang terkandung dalam novel Surga Yang Harus Ku Jaga karya Sean Hasyim terhadap pendidikan masyarakat muslim. Rancangan penelitian ini menggunakan metode deskriptif kualitatif dengan pendekatan Pragmatik Reseptif.Metode kualitatif memberikan perhatian terhadap data alamiah, data dalam hubungannya dengan konteks keberadaannya. Hasil dari penelitiaan ini adalah ditemukanya nilai-nilai pendidikan islam. Pertama, Tafakur / ingat kepada allah. Kedua kesabaran.Ketiga berbakti kepada orang tua.
\end{abstract}

Kata kunci: pendidikan, Islam, pragmatik, reseptif, Sean Hasyim.

Abstract: This research is based on Islamic education, namely education that developed from the fundamental values contained in the Al-Qur'an and Al-Hadith. This study is using novel media. While Novel which can be a medium of education is a novel that contains values that educate humans. That is a story that able to educate the mind, imagination and ethics of a child, and develop the potential of knowledge possessed. The purpose of this study are (1) to describe the values of Islamic Education contained in Novel Surga Yang Harus Ku Jaga By Sean Hasyim; (2) to find out the relevance of the values of Islamic Education contained in the Novel Surga Yang Harus Ku Jaga By Sean Hasyim on the education of Muslim communities. The design of this study uses a descriptive qualitative method with a receptive pragmatic approach. The descriptive qualitative method gives attention to natural data, data in relation to the context of its existence. The result of this research is the discovery of the values of Islamic education. First, Tafakur/ remember Allah. Second patience, patience will give someone a chance to read life issues.Third, devote to parents.

Keywords: education, Islam, pragmatic, receptive, Sean Hasyim

\section{PENDAHULUAN}

Pendidikan menurut Islam atau pendidikan yang Islami, yaknipendidikan yang dipahami dan dikembangkan dari ajaran dan nilai-nilaifundamental yang terkandung dalam sumber dasarnya, yaitu Al-Qur'an danAs-sunnah. Dalam pengertian ini, pendidikan Islam dapat 
berwujudpemikiran dan teori pendidikan yang mendasarkan diri atau dibangun dandikembangkan dari sumbersumber dasar tersebut.Pada dasarnya seoranginsan lahir dalam kedaan fitrah " bertauhid " yaitu dalam keadaan suci,bagaimana keadaan kelak di masa yang akan datang bergantung pada didikanorang tuanya. Hal ini dijelaskan oleh Rasulullah dalam haditsnya yangberbunyi "Seorang bayi tidaklah dilahirkan melainkan dalam kesucian (fitrah). Kemudian kedua orang tuanyalah yang membuat menjadi Yahudi atau Nasrani atau Majusi”. (H.R Bukhari dalam Imam Turmudzi, 2003 : 1083).

Hadits di atas menjelaskan betapa besar pengaruh pendidikan orangtua terhadap pendidikan anak-anaknya. Ia bisa menentukan keadaan anaknyakelak di masa datang. Oleh karena itusudah seharusnyalah para orang tuabersungguh sungguh dan berhati-hati dalam mendidik anaknya. Masa depananak sangat tergantung kepada pendidikan, pengajaran, dan lingkungan yangdiciptakan oleh orang tuanya.Apabila lingkungannyaIslami, maka anak akan memiliki kecenderungan kepada agama. Jika inginterwujudnya suatu masyarakat yang baik, tertib dan diridhai Allah mulailahdari keluarga (Ruhama, 1994 : 64).

Novel sebagai karya fiksi menawarkan sebuah dunia, dunia yang berisi model kehidupan yang diidealkan, dunia imajinatif yang dibangun melalui unsur intrinsiknya seperti peristiwa, plot, tokoh (dan penokohan), latar, sudut pandang, dan lain-lain yang kesemuanya tentu saja juga bersifat imajinatif. Jadi, dalam karya sastra khususnya dalam novel, tidak hanya berupa kisah yang diambil dari kehidupan nyata sehari-hari, melainkan diambil dari imajinasi atau daya khayal seseorang.
Sebuah karya satra, termasuk novel biasanya menggambarkan kehidupan pada saat karya sastra itu ditulis. Karya sastra seperti novel selalu menghadirkan berbagai macam nilai-nilai kehidupan dan nilai-nilai pendidikan seperti nilai moral, sosial, budaya, dan religi yang patut untuk diteladani. Oleh karena itu, novel sebagai karya sastra merupakan salah satu jenis dari bacaan masyarakat, turut memberikan pengaruh besar terhadap pembentukan pola pikir masyarakat pembacanya. Novel sebagai salah satu media alternatif bacaan pun harus mampu memberikan hal-hal positif yang ada di dalamnya.

Sekolahsebagailembagapendidikan, bertugasmemberikan pembelajaran moral kepada siswanya. Pembelajaran moral ini dapatdilakukandengan memberikanpembinaandalam pembelajarankaryasastra.Karya sastra berupa buku-buku yang berisi cerita yang baik turut memberikan pengaruh dalam pembentukan watak siswa. Maka dari itu, apa yang tertulis dalam karya sastra khususnya novel, merupakan observasi yang tajam dari pengarang terhadap realitas yang terjadi disekelilingnya. Membaca karya sastra memungkinkan seseorang mendapatkan masukan tentang nilai-nilai kehidupan positif yang patut diteladani, baik terhadap diri sendiri, orang lain, maupun Tuhan. Dari pemaparan di atas, diharapkanpembelajaran sastra di sekolah turut berpengaruh dalam pembentukan watak siswa.

PendidikanIslam dalam Novel Surga Yang Harus Ku Jaga Karya Sean Hasyim merupakan salah satu dari sekian usahauntuk memanfaatkan metode cerita yang menarik berupa novel yang menjadikan nilai-nilai pendidikan mudah dicerna oleh para pembacanya. Dimana novel tersebut merupakan sebuah karya seni yang sarat akan nilai nilai edukatif bagi remaja dan anak-anak yang 
mengajak kepada pembacanya untuk ikhlas menerima segalaketentuan Allah juga agar senantiasa selalu mendekatkan diri kepada SangPencipta.

Memulai karier di dunia entertainment sebagai juara favorit ajang pemilihan model majalah remaja, Sean Hasyim kemudian aktif sebagai aktor profesional. Berbagai judul sinetron FTV fans film telah ia bintangi, keberhasilannya dalam dunia akting tidak lantas membuat pria kelahiran Jakarta, 23 Oktober ini puas diri. Setelah sukses dengan karya novel pertamanya berjudul tentang "Ibu, Sahabat dan Aku". Di tahun 2016 ini Sean Hasyim kembali meluncurkan novel inspiratif yang ia ramu dari kejadian nyata yang ia jumpai dalam kehidupan sehari-hari. Novel kedua berjudul "Surga yang Harus Kujaga" adalah penggalan pengalaman dan pembelajaran hidup yang ingin ia ceritakan kepada penggemar dan pembacanya di seluruh Indonesia.

Berangkat dari sinilah penulis tertarik untuk menulis tesis inidengan pendekatan prakmatik reseptif. Pragmatik Resepsi sastra merupakan aliran sastra yang meneliti teks sastra dengan mempertimbangkan pembaca selaku pemberi sambutan atau tanggapan. Dalam memberikan sambutan dan tanggapan tentunya dipengaruhi oleh faktor ruang, waktu, dan golongan sosial(Fananie , 2000:112).

Berdasarkan latar belakang yang dikemukakan di atas, maka peneliti akan mengangkat permasalahan tersebut dalam judul tesisNilai-nilai Pendidikan Islam dalam Novel Surga Yang Harus Ku Jaga Karya Sean Hasyim (Pendekatan Pragmatik Reseptif), dengan alasan: Pertama, penulis memandang banyak nilai pendidikan yang ada dalam novel Surga Yang Harus Ku Jaga yang layak untuk diketahui oleh berbagai kalangan, terutama bagipeserta didik dalam menempuh pendidikannya. Kedua, penulis berusahamenggali nilai-nilai pendidikan Islam yang terkandung dalam novel Surga Yang Harus $\mathrm{Ku}$ Jaga. Sehingga akan menambah khazanah baru dalam dunia pendidikan Islam.

\section{METODE PENELITIAN}

Rancangan penelitian ini menggunakan metode deskriptif kualitatif dengan pendekatan Pragmatik Reseptif. Metode kualitatif memberikan perhatian terhadap data alamiah, data dalam hubungannya dengan konteks keberadaannya. Cara-cara inilah yang mendorong metode kualitatif dianggap sebagai multimetode sebab penelitian pada gilirannya melibatkan sejumlah besar gejala sosial yang relevan. Penelitian kualitatif adalah prosedur penelitian yang menghasilkan data deskriptif berupa kata-kata tertulis atau lisan dari orang-orang dan perilaku yang diamati (Bogdan dan Taylor dalam Moleong, 1990: 31).

Metode yang digunakan dalam penelitian ini adalah analisis konten. Analisis konten yaitu metode penelitian untuk menghasilkan deskripsi yang objektif dan sistematik mengenai isi.Penelitian sastra tergolong ilmu geistewissenschafen, artinya telaah ilmu kemanusiaan. Penelitian serupa sering disebut juga telaah humaniora. Hanya saja, subyeknya dapat berupa teks sastra dan tentang sastra.

Subroto (1992:34) menyatakan bahwa data adalah semua informasi atau bahan yang disediakan oleh alam (dalam arti luas) yang harus dicari atau dikumpulkan dan dipilih penulis.Penelitian ini menggunakan teknik pengumpulan data berupa teknik pustaka, simak, dan catat. Teknik pustaka adalah teknik menggunakan sumbersumber tertulis untuk memperoleh data. Teknik simak adalah suatu metode 
pemerolehan data yang dilakukan dengan cara menyimak suatu penggunaan bahasa (Sudaryanto dalam Mahsun, 2005: 90).

Pengumpulan data dilakukan dengan langkah-langkah sebagai berikut. (1) Pembacaan secara intensif, cermat dan teliti terhadap novel untuk mendapatkan data utama, dan membaca informasi berita di surat kabar atau laman yang ada kaitannya dengan fokus penelitian; (2) Pemarkahan (penandaan) dilakukan pada data-data yang sesuai dengan penelitian; data yang ditandai adalah data untuk mendapatkan gambaran dan pemahaman dalam novel atau yang sesuai fokus penelitian; (3) Pemilahan sesuai dengan fokus dilakukan pada data yang telah ditandai; dan dikelompokkan sesuai dengan kajian; (4) Pengelompokkan sesuai dengan fokus penelitian; (5) Penyajian data dalam bentuk tabel-tabel; (6) Pengodean data, misalnya (7) Pengecekan ketercukupan data serta melakukan pengumpulan data jika data belum tercukupi.

\section{HASIL DAN PEMBAHASAN Nilai Pendidikan Islam}

Di dalam novel Surga Yang Harus Kujaga karya Sean Hasyim mengungkapkan beberapa hal terkait dengan nilai-nilai pendidikan islam. Adapaun dalam novel tersebut ditemukan nilai-nilai pendidikan Islam.Diantara nilai-nilai pendidikan Islam adalah tafakur, sabar dan berbakti kepada orang tua.

Tafakur adalah usaha untuk selalu mendekatkan diri kepada Allah Swt. Tafakur juga bisa dikatakan sebagai perenungan untuk selalu mengingat, menganalisa dan meyakini secara pasti lebih dekat dengan Allah Swt. Seperti halnya ayat allah yang menerangkan tentang tafakur "Yaitu orang-orang yang beriman, dan hati mereka aman tenteram dengan dzikir pada Allah. Ingatlah dengan dzikir pada Allah itu, maka hatipun akan merasa aman dan tenteram". (Ar-Ro'd :2010:28)

Agar tujuan tersebut tercapai, rasulallah Saw. Telah memberi ramburambu agar kita tidak salah dalam bertafakur. Rasulallah Saw. Memerintahkan kita untuk bertafakur mengenai makhluk ciptaan Allah Swt. Beliau melarang kita berpikir tentang zat Allah karena manusia memang tidak bisa menjangkaunya. Jadi pada intinya manusia disuruh untuk mendekatkan diri kepada Allah seperti kutipan berikut:

Pelajaran pagi yang begitu membelenggu hati menyadarkan diri ini yang seringkali tak punya rasa empati dan simpati. Tuhan memang punya banyak cara buat menyadarkan hamba-Nya yang sebenarnya terus berusaha dia sayang. (Hasyim, 2016:99)

Kesabaran akan memberikan kesempatan seseorang membaca persoalan hidup dalam kacamata yang lebih luas.Sabarlah yang membuat orang bisa menguasai dirinya sendiri.Sehingga kesabaranlah yang benar-benar menjadi penolong orang-orang beriman.Setiap hari Hasyim selalu berusaha membantu kerja ibunya.Karena Hasyim melihat bahwa kebutuhan keuangan sehari-hari tidak sedikit. Ibu Hasyim hanya sebagai penjahit di wilayah kompleks rumahnya. Ibu Hasyim tidak pernah mengeluh dengan apa yang dikerjakan, bahwa dengan kegigihan dan kesabaran, Ibu Hasyim bisa membesarkan Hasyim seperti dalam kutipan berikut.

Tapi ibu tetap tegar, dengan bekal mesin jahit peninggalan nenek, ibu menerima jahitan di kompleks perumahan kami yang ada di pinggiran Jakarta Timur.(Hasyim, 2016:9)

Data di atas menunjukkan bahwa Ibu Hasyim selalu tekun dan rajin, serta bekal ulet dan kesabaran bisa menjalani kehidupan sehari-hari.

Perlu ditegaskan kembali, bahwa birrul waalidain (berbakti kepada kedua orang tua), lebih dari sekadar berbuat ihsan (baik) kepada keduanya. Namun 
birrul walidain memiliki nilai-nilai tambah yang semakin 'melejitkan' makna kebaikan tersebut, sehingga menjadi sebuah 'bakti'.Dan sekali lagi, bakti itu sendiripun bukanlah balasan yang setara untuk dapat mengimbangi kebaikan orang tua.Namun setidaknya, sudah dapat menggolongkan pelakunya sebagai orang yang bersyukur.

Seperti halanya Hasyim, ketika punya masalah dan berusaha untuk menutupi.Tertapi, ada penjual makan yang justru tahu tentang keadaan Hasyim. Karena Hasyim terlihat jelas di raut mukanya ada segudang masalah, dan penjual makanan tersebut sangat memahami, seperti halnya kutipan berikut.

"Janganlah sakiti hati ibu!"

"bukan nyakitin Pak...!"

"Apalagi malah mas marah-marah..." (Hasyim, 2016:28)

Pada malam hari, Hasyim tidak pulang ke rumah.Hasyim sengaja berjalan di malam hari dengan tujuan untuk menghilangkan penat.Karenanya wajah Hasyim sangat terlihat jelas ketika membeli makanan.Sehingga penjual makanan tahu kalau Hasyim punya masalah.

\section{Relevansi Pendidikan Islam}

Sebuah kata-kata yang biasa bila hanya didengarkan, tetapiperhatian akan terasa sangat berharga bila kita sedang sedang mengalami banyak masalah. Dengan suatu perhatian seseorang bisa memberikan suatu suport yang sangat berarti bagi orang yang diperhatikan. Seperti pada kutipan berikut :

Dan lebih ngeselin adalah, sudah tahu aku shooting, sempatnya ibu tanya, "gimana kuliah, jadi daftar ulang kapan?" Sebab aku sudah tertinggal, libur satu semester ini.(Hasyim, 2016:7)

Jika kita amati keadaan, sebenarnya Ibunya sangat perhatian dengan Hasyim. Orang tua mana yang tidak mau anaknya sukses. Ibu Hanyim selalu perhatian kepada Hasyim. Setiap saat ia selalu berharap Hasyim menjadi yang terbaik.

Pekerjaan Hasyim sebagai aktor sangat menguras tenaga.Ia setiap hari berangkat pagi. Pulangnya larut malam.Keseringan seperti ini, tentunya Ibu yang menunggu di rumah kadang mendahului tidur karena terlalu lama menunggu. Hasyim pulang ke rumah selalu di atas jam 22.00 WIB. Pada saat ibunya tidur pulas, Hasyim baru pulang.Berulang kali bel dibunyikan, telephon ibunya, tetap saja tidak ada respon karena ibunya sudah tidur. Melihat keadaan seperti itu, Hasyim sangat kesal dan marah, seperti kutipan berikut.

Aku kesal sekali, beberapa kali telepon ke HP ibu tak juga diangkat.Mungkin ibu kesal karena sejak sore aku tidak mau menerima teleponnya. Semua SMS aku baca dan segera hapus, isinya basi menurutku! (Hasyim, 2016:7)

Pagi, siang, sore, petang, dan malam Ibu hasyim selalu meminta kabar lewat sms.Tetapi Hasyim tidak pernah membalasnya.Ibu hasyim sudah lama menunggu di rumah.Namun haysim juga tidak kunjung memberikan kabar.Karena sudah lama menunggu, ibu hasyim tidur dahulu.Tidak tahunya ketika Hasyim pulang, justru jengkel dan marah.

Hasyim tambah jengkel ketika ibunya marah-marah. Ibu Hasyim tentunya punya alasan lain ketika marah. Ibu mana yang tidak marah jika anaknya setiap hari pulang larut malam. Marah Ibu, bukan berarti tidak sayang. Tetapi terlalu perhatiannya kepada anak.Keadaan di rumah semakin tidak harmonis.Hayim tidak mau bertemu atau menatap wajah ibunya.Hasyim terpaksa keluar dari rumah dan ingin mencari hiburan untuk menghilangkan penat.

Hasyim kian marah ketika ia mulai sering sakit gara-gara jadwal padat dan lupa makan. Perhatian ibunya tiada diperhatikan. Hasyim justru malah tidak suka dengan aturan dan pembicaraan ibu 
yang menyangkut tentang pekerjaan dan kesehatan, seperti kutipan berikut :

Aku bertengkar hebat dengan ibu.Hanya garagara aku sering sakit karena lupa makan, sehabis shooting langsung tidur tanpa mau peduli kesehatan, sakit, tidak kuliah, dan jika sudah begitu, cerewet ibu kambuh.(Hasyim, 2016:16)

Sebagai manusia, jangan sering marah kepada siapa saja.Apalagi sampai bertengkar.Jagalah selalu hubungan baik dengan siapa saja.Bertengkar itu tidak baik.Apalagi bertengkar dengan orang tua.Lebih-lebih dengan seorang ibu.Perlu diketahui bahwa, ibu adalah surga.Maka jaga dan rawatlah.Perlakukan yang baik.Jangan buat ibu kesal atau sampai marah. Karena siapa yang bisa membahagiakan orang tua, pasti akan mendapatkan kebahagiaan.

Ibu dengan seorang anak kecil yang digendong kemana-mana.Dia selalu berusaha memberikan yang terbaik untuk anaknya.Bekerja setiap hari.Tidak kenal siang malam. Yang ia pikirkan adalah dapat penghasilan, yang dipakai untuk anak-anaknya, seperti kutipan berikut :

"Ibu itu bekerja keras siang dan malam, demi membiayai kehidupan mereka. Kerja apa saja asal dengan menggendong sang anak di punggungnya!" (Hasyim, 2016:35)

Ketika Hasyim sedang ada masalah dengan ibunya, beberapa hari Hasyim tidak pulang ke rumah.Ia sering tidur di rumah temannya. Kadang juga tidur di tempat shooting. Hasyim sengaja tidak pulang karena ia tidak ingin bertemu dengan ibunya. Karna, jika ia bertemu ibunya ia selalu ingin marah. Ia selalu jengkel dan ingin selalu bertengkar.

Ibu Hasyim, sangat perhatian kepada Hasyim. Ia bahkan rela berkorban demi Hasyim. Semua dilakukan demi membahagiakan Hasyim, seperti kutipan berikut.

"Pasti semua ibu yang baik tentu mau berkorban bagi anaknya, beda versi tentu saja apa pengorbanannya!Ini kan hanya sebuah contoh!" (Hasyim, 2016:43)

Ibu adalah sosok paling tegar yang pernah ada, yang rela mengorbankan apapun demi menghidupi buah hatinya. Se-arogan apapun sosok ibu yang pernah ada, mereka tidak akan mungkin menjebloskan buah hatinya sendiri ke dalam jurang. Ia akan tulus berjuang melindungi sampai kapanpun, demi keselamatan dan kebaikan anaknya.

Memakan harta orang lain pengertiannya mencakup segala apa yang diambil dari orang lain, baik melalui cara yang zalim seperti merampas, khianat, mencuri dan berbudi, ataupun dengan cara penipuan seperti mengadakan kontrak palsu dengan orang lain.

Mencuri salah satu bagian yang merugikan orang lain. Karena mencuri adalah merampas yang bukan haknya.Hasyim kerap kali diingatkan oleh ibunya.Jangan sekali-kali mencuri.Kalau memang tidak bisa untuk membeli, disuruh untuk meminta.Karena ibu Hasyim tidak ingin anaknya menjadi seorang pencuri.

Hasyim juga sering diingatkan oleh teman akrabnya.Jangan sampai menjadi seorang pencuri. Mengambil hak yang bukan haknya, bahkan teman akrab Hasyim kerap memberikan contohcontoh supaya tidak menjadi seorang pencuri, seperti kutipan berikut :

"Kita miskin, tapi nggak harus jadi pencuri" lalu si ibu mengambil rotan dan mulai memukul anaknya keras. Biarpun ibu sayang pada anaknya, ia harus mendidik anaknya sejak kecil!. (Hasyim, 2016:50)

Alhamdulillah, segala puji hanyalah milik Allah.Dia-lah yang telah memberikan ampunan kepada setiap pelaku dosa.Dan Allah pula yang telah melipat-gandakan pahala bagi para pelaku kebajikan.Dia melimpahkan berbagai kebaikan dan kenikmatan kepada segenap makhlukNya.

Ketahuilah, pemberian terbaik yang Allah anugerahkan kepada seorang hamba adalah keimanan dan ketakwaan.Kekayaan dan kecukupan hidup, hendaknya tidak menjadi kendala 
seseorang untuk bertakwa.Dia juga harus yakin, bahwa iman dan takwa merupakan nikmat dan karunia Allah semata.

Jika ada masalah hendaknya kita langsung meminta maaf.Seperti halnya kejadian pada anak.Seorang ibu yang tidak tahu pekerjaan anaknya, tiba-tiba membelikan kado buat ibunya.Karena harga yang sangat mahal, tentu ibunya mulai curiga. Dari mana ia dapatkan uang sebanyak itu.

Dari ulasan di atas perlu kita mengingat yang pernah disampaian oleh pada ulama tentang cerita sahabat yang paling spesial."Akan datang kepada kalian seorang laki-laki ahli syurga" kata Rasululloh.Sontak mendengar hal itu para sahabat menjadi riuh, siapakah ahli syurga yang dimaksud Rasululloh? Apakah dia orang yang paling berani dalam berjihad?Yang paling banyak shoumnya?Sedekah dan qiyamul lailnya paling rajin?Tiga hari berturut-turut Rasululloh mengatakan hal yang sama, dan yang melintas setelah itu selalu sosok yang sama, yakni salah seorang sahabat Anshar. Abdullah bin Amr bin Ash sangat penasaran, sehingga beliau bertekad mencari tahu rahasia amalan sahabat Anshar tersebut. Strategi pun disusun agar Abdullah bisa bermalam selama tiga hari di rumah sang sahabat Anshar."Aku memiliki persoalan dengan Ayahku, sudikah engkau membolehkan aku bermalam di rumahu selama tiga hari?" tahya Abdullah."Tentu saja, silakan!" jawab sahabat Anshar itu.Di hari pertamanya Abdullah tidak menemukan adanya ibadah istimewa yang dilakukan sahabat Anshar itu."Mungkin besok aku akan mengetahui rahasianya." ujarnya dalam hati. Namun sayang hingga hari ketiga, Abdullah tidak menemukan apa yang dia ingin ketahui dari sahabat Anshar itu. Tentu saja Abdullah bingung karena sahabat Anshar itu tidak pernah shoum sunnah, Sholat malam pun tidak, lantunan dzikir juga tidak pernah Abdullah dengar dari lisan Sahabat Anshar itu. Di hari ketiga, akhirnya Abdullah menyerah dan mengatakan yang sesungguhnya kepada sahabat Anshar itu bahwa dia tidak pernah bertengkar dengan Ayahnya, dia hanya ingin tahu apa amalan yang sahabat Anshar itu lakukan sehingga Rasululloh menyebutnya sebagai ahli surga."Beritahukanlah aku rahasia amalanmu agar aku bisa melakukannya dan menjadi ahli syurga sepertimu" kata Abdullah."Aku tidak memiliki amalan selain engkau lihat selama tiga hari menginap di rumahku," katanya. Jawaban itu tidak memuaskan Abdullah, akhirnyaia pun minta ijin untuk pulang. Namun tak jauh melangkah, Sahabat Anshar itu memanggilnya ."Benar sekali amalanku hanya yang engkau lihat selama ini, namun ada yang lupa aku ceritakan padamu yaitu sebelum aku tidur kuingat semua orang yang perbuatannya pernah menyakitiku dan aku tidak akan tidur kecuali telah memaafkannya." Mendengar itu Abdullah tersenyum puas karena apa yang ia inginkan akhirnya telah ia dapatkan.

Sikap tolong menolong adalah ciri khas umat muslim sejak masa Rasulullah Șalla Allah 'Alayhi wa Sallam. Pada masa itu tak ada seorang muslim pun membiarkan muslim yang lainnya kesusahan, hal ini tergambar jelas ketika terjadinya hijrah umat muslim Mekkah ke Madinah, kita tahu bahwa kaum ansor atau Muslim Madinah menerima dengan baik kedatangan mereka yang seiman dengan sambutan yang meriah, kemudian mempersilahkan segalanya bagi para muhajirin.

Hasyim kian lupa dengan keadaan ibunya di rumah.Ia hanya sibuk shooting. Segala upaya ibunya untuk mengajak dan mengerjakan kebaikan, Hasyim selalu mengabaikan.Bahkan untuk sekedar 
obrolan santai saja, Hasyim tidak mau. Pada suatu saat, Hasyim sadar ketika ban motornya kempes. Tidak ada jalan lain kecuali harus segera ke tempat shooting. Karena hari itu, Hasyim harus tes untuk pemilihan aktor terbaik.Akhirnya bapakbapak menolong Hasyim.Sampai akhirnya Hsayim tetap menjadi aktor pertama. Dan di saat seperti itu, Hasyim baru sadar betapa pentingnya saling tolong-menolong sesama manusia, seperti kutipan berikut:

Aku nyaris telar ke lokasi shooting, beruntung ditolong bapak itu.Saat itu shooting hari pertama penentuan aku bisa dipakai jadi main talent tidaknya di sinetron striping pertamaku.Dan berkat bantuan bapak itulah, aku bisa profesional kerja di hari pertama kerja. (Hasyim, 2016:60)

Dan tolong-menolonglah kamu dalam (mengerjakan) kebajikan dan takwa, dan jangan tolong-menolong dalam berbuat dosa dan pelanggaran. Dan bertakwalah kamu kepada Allah, sesungguhnya Allah amat berat siksaNya [al-Mâidah/5:2]

Mengeluh merupakan sebuah kebiasaan buruk yang sangat sering dilakukan oleh banyak orang. Kali ini KatMut.com akan berbagi kata-kata mengeluh yang akan membuat Anda berhenti mengeluh dan berubah menjadi seorang yang bersyukur dan bijak dalam menghadapi setiap masalah.

"Tugas akhirnya yang belum Bu, puisng!Banyak shooting!" (Hasyim, 2016:73)

Apabila Anda merupakan seorang yang sering mengeluh, sebaiknya Anda mulai menghentikan kebiasaan buruk ini. Karena mengeluh tidak akan menyelesaikan masalah yang Anda hadapi, malahan mengeluh hanya akan membuang waktu dan tenaga Anda. Seperti yang dikatakan oleh T Harv Eker, pengarang buku Secrets of the Millionaire Mind, mengeluh hanya akan menambah masalah Anda:

Jangan mengeluh bila Anda menghadapi kesulitan tetapi lakukanlah hal berikut ini. Tutuplah mata Anda, tarik nafas panjang, tahan sebentar dan kemudian hembuskan pelan-pelan dari mulut Anda, buka mata Anda, tersenyumlah dan pikirkanlah bahwa suatu saat nanti Anda akan bersyukur atas semua yang terjadi pada saat ini.

\section{SIMPULAN}

Di dalam novel Surga Yang Harus Kujaga karya Sean Hasyim mengungkapkan beberapa hal terkait dengan nilai-nilai pendidikan islam. Adapaun dalam novel tersebut ditemukan nilai-nilai pendidikan Islam.Diantara nilai-nilai pendidikan Islam adalah tafakur, sabar dan berbakti kepada orang tua.

Kesabaran akan memberikan kesempatan seseorang membaca persoalan hidup dalam kacamata yang lebih luas. Kesabaranlah yang menjadi pintu seseorang menemukan kemudahan saat mengalami kesulitan.Sabarlah yang membuat orang bisa menguasai dirinya sendiri.Sehingga kesabaranlah yang benar-benar menjadi penolong orangorang beriman.Setiap hari Hasyim selalu berusaha membantu kerja ibunya.Karena Hasyim melaihat bahwa kebutuhan keuangan sehari-hari tidak sedikit. Ibu Hasyim hanya sebagai penjahit di wilayah kompleks rumahnya. Ibu Hasyim tidak pernah mengelu dengan apa yang dikerjakan, bahwak dengan kegigihan dan kesabaran, Ibu Hasyim bisa membesarkan.

Perlu ditegaskan kembali, bahwa birrul waalidain (berbakti kepada kedua orang tua), lebih dari sekadar berbuat ihsan (baik) kepada keduanya.Namun birrul walidain memiliki nilai-nilai tambah yang semakin 'melejitkan' makna kebaikan tersebut, sehingga menjadi sebuah 'bakti'. Dan sekali lagi, bakti itu sendiripun bukanlah balasan yang setara untuk dapat mengimbangi kebaikan orang tua.Namun setidaknya, sudah dapat 
menggolongkan pelakunya sebagai orang yang bersyukur.

\section{DAFTAR PUSTAKA}

BurhanNurgiyantoro.2005.TeoriPengkaji anFiksi.Yogyakarta: GajahMada Press.

Damono, Sapardi Djoko. 1979. Sosiologi Sastra: Sebuah Pengantar Ringkas. Jakarta Pusat: Pusat Pembinaan dan Pengembangan Bahasa.

Daradjat, Zakiah,dkk. 2012. Ilmu Pendidikan Islam. Jakarta: PT Bumi Aksara.

Darajat, Zakiah. 1994.Pendidikan Islam dalamKeluargadanSekolah. Jakarta: Ruhama.

Darmadi, Hamid. 2011. Metode Penelitian Pendidikan,cet.2. Bandung: Alfabeta

Departeman Pendidikan Nasional, 2007, Kamus Besar Bahasa Indonesia, cet. 4 Jakarta: Balai Pustaka.

Departemen Agama RI. 2015.Al-Qur'an dan Terjemah. Jakarta: Yayasan Penyelenggara Penerjemah AlQur'an

Endraswara, Suwardi. 2004. Metodologi Penelitian Sastra. Yogyakarta. Penerbit Pustaka Widyatama.

Herman J. Waluyo. 2006. Pengakajian dan Apresiasi Prosa Fiksi. Surakarta: UNS Press.

Mahayana, Maman S. Ekstrinsikalitas Sastra Indonesia. Jakarta: PT RajaGrafindo Persada. 2007
Mahfud.1997. Pengantar Ilmu-Ilmu Sosial. Jakarta: Sinar harapan.

Minderop, Albertine. Metode Karakterisasi Telaah Fiksi. Jakarta: Yayasan Obor Indonesia 2005

Moleong, Lexy J. Metodologi Penelitian Kualitatif. Bandung: PT Remaja Rosdakarya. 2011

Muhaimin, 2012.ParadikmaPendidikan Islam, cet.5.Bandung : PTRemajaRosdakarya.

Mujib, Abdul, 2008. M.Ag. dan Dr. Jusuf Mudzakkir, M.Si, Ilmu Pendidikan Islam, cet. 2. Jakarta: Kencana Prenada Media Group.

Nadia, Asma, 2015.cinta Di Ujung Sajadah. Depok: AsmaNadia PublishingHouse.

Nurgiyanto, Burhan, 2007.TeoriPengkajianFiksi, cet. 6.Yogyakarata: Gajah madaUniversity Pres.

Pradopo, Rachmat Djoko. 2007. Pengkajian Puisi. Yogyakarata: Gajah madaUniversity Pres.

Sukardi. 2011. Metodologi Penelitian Pendidikan,cet.10. Jakarta: Teruna Grafika

Yusuf L. N, Syamsul dan Nani M. Sugandhi, 2011.Perkembangan Peserta Didik.Jakarta: PT Raja Grafindo Persada.

Wellek, Rene dan Austin Warren. 1990. Teori Kesusastraan Terjemahan Melani Budianto. Jakarta. PT Gramedia. 


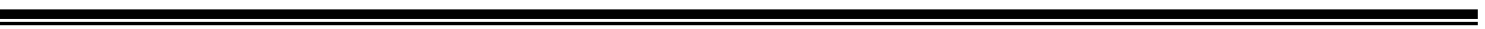

